\title{
Peak incidence of distal radius fractures due to ice skating on natural ice in The Netherlands
}

\author{
Arno P. W. van Lieshout • Christiaan J. van Manen • \\ Karel J. du Pré • Ydo V. Kleinlugtenbelt • \\ Rudolf W. Poolman · J. Carel Goslings $\cdot$ Peter Kloen
}

Received: 7 January 2010/Accepted: 11 April 2010/Published online: 12 May 2010

(C) The Author(s) 2010. This article is published with open access at Springerlink.com

\begin{abstract}
An increase of distal radius fractures was seen in 2009 when an extended cold spell allowed natural ice skating in Amsterdam. This resulted in overload of our Emergency Departments and operating rooms. This study reports patient and fracture characteristics of these injuries. We also determined potential skating-related risk factors. All patients who sustained a distal radius fracture during natural ice skating between January 3 and January 12, 2009 were included. Patient and fracture characteristics, treatment, validated outcome (Quick DASH) at 3 months after injury were determined. Natural ice skating accounted for a 5.5-fold increase of distal radius fractures (92 fractures) compared to a similar time period without natural ice skating in 2008. Fracture types were AO-type A, $n=50$, type $\mathrm{B}, n=11$ and type C, $n=31$. Twenty-eight patients were casted without reduction. Fifty-four patients underwent at least one reduction before
\end{abstract}

A. P. W. van Lieshout $(\bowtie) \cdot$ P. Kloen

Department of Orthopedic Surgery, Academic Medical Centre, Meibergdreef 9, 1105 AZ Amsterdam, The Netherlands

e-mail: a.v.lieshout@hotmail.com

C. J. van Manen · J. C. Goslings

Trauma Unit, Department of Surgery, Academic Medical Centre, Meibergdreef 9, 1100 DD Amsterdam, The Netherlands

K. J. du Pré

Department of Orthopedic Surgery, Slotervaart Hospital, Louwesweg 6, 1066 EC Amsterdam, The Netherlands

Y. V. Kleinlugtenbelt · R. W. Poolman

Department of Orthopedic Surgery, Onze Lieve Vrouwe

Gasthuis, Joint Research, Oosterpark 9, 1091 AC Amsterdam,

The Netherlands casting. The non-operative group consisted of 67 patients (68 fractures, male/female 18/49) with an average age of 55.5 years. Twenty-three patients (24 fractures) underwent internal fixation. Quick DASH for the whole group was a mean of 23.1 points (range 0-95). The mean Quick DASH for the non-operatively treated group was 19.9 points (range 0-95), for the operatively treated group 31.7 points (range 2-65). Distal radius fractures increased 5.5 -fold during a period with natural ice skating. Women aged 50 and over were predominantly affected. Most fractures were extra-articular, and the vast majority was treated non-operatively. Utilization of wrist-protecting devices should be considered during future natural ice periods.

Keywords Distal radius fractures - Ice skating

\section{Introduction}

Skating on natural ice was first described in literature in the sixteenth century and has been extremely popular as a winter activity since the seventeenth century in The Netherlands as illustrated on numerous paintings from famous Dutch painters (Fig. 1). However, due to global warming, the average winter temperature has increased during the last 50-60 years and the opportunity to skate on natural ice has become rare in The Netherlands. However, in late December of 2008 and the beginning of January 2009, temperatures in The Netherlands dropped below $0^{\circ} \mathrm{C}$ and most surface waters (ponds, lakes and canals) froze for the first time in 10 years, allowing skating on natural ice in the entire country for over a week. This resulted in-literally-millions of people of all ages (population 16 million) putting on their skates. 


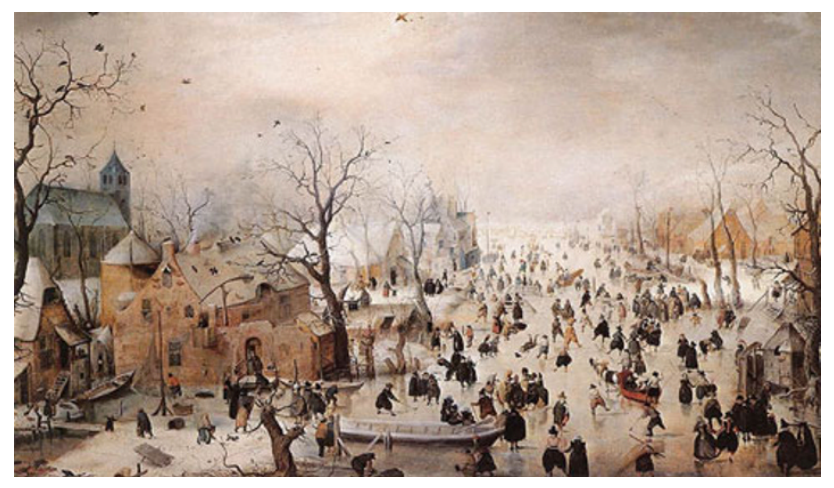

Fig. 1 Winter landscape with ice skaters by Hendrick Avercamp (1608)

Offices and schools closed to enable people to skate. Emergency Departments (EDs) were flooded with patients that sustained ice skating injuries, resulting in long waiting times at these EDs. In three teaching hospitals in Amsterdam, an increase in patients with distal radius fractures was seen during this period of 9 days, compared to the same period in 2008 , when there was no natural ice. This increase in incidence of distal radius fractures resulted in an overload at the EDs, outpatient clinics, radiology departments and cast rooms in addition to a newly formed wait list for surgery.

The aim of this study is to report characteristics of the patients and their sustained wrist fractures, as well as potential skating-related risk factors. We hypothesized that during the period of skating on natural ice, the incidence of distal radius fractures increased. Utilization of wristprotecting devices was evaluated.

\section{Patients and methods}

In this descriptive case series, we have evaluated patients with distal radius fractures resulting from a fall on ice during skating on natural ice in a 9-day period in 2009 . From the logbooks of three EDs in three teaching hospitals, all patients who sustained a distal radius fracture between January 3 and January 12, 2009 were identified. If the cause of the fall was not registered as a skating injury, patients were excluded. As comparison, logbooks of a similar length period of 9 days in 2008, without freezing conditions, were analyzed for distal radius fractures.

Standard diagnostics consisted of postero-anterior and lateral radiographs. If a fracture was noted, the attending orthopedic or general trauma surgeon was notified. Fractures with less than $10^{\circ}$ dorsal/palmar angulation, no intra-articular step-off of more than $2 \mathrm{~mm}$, and/or radial shortening less than $5 \mathrm{~mm}$ were treated with a plaster cast without the need for reduction or additional radiographic studies. If indicated (dorsal tilt $>10^{\circ}$, intra-articular step-off $>2 \mathrm{~mm}$, radial shortening $>5 \mathrm{~mm}$ ), a closed reduction was performed in the ED using local anesthetic delivered into the fracture hematoma by syringe. A plaster cast was applied, followed by post-reduction postero-anterior and lateral radiographs. If needed, a second reduction was performed followed by new radiographs.

All patients were discharged with a follow-up appointment in 5-10 days. In case of comminution and/or an unstable fracture pattern, patients were informed that a surgical procedure might be necessary. CT scanning was selectively performed for decision-making and pre-operative planning. Patients who were treated non-operatively were seen in the outpatient clinic at 1, 2, 6 and 12 weeks post-injury. Radiographs were taken at all control visits except on the 12-week visit.

At 3 months after the injury, the follow-up consisted of a physical examination, expressed in neutral null method for range of motion. Subjective function was evaluated at 3 months by using the disability/symptom section of the validated Quick DASH questionnaire in Dutch [10]. Two senior attending surgeons (one experienced trauma surgeon and one fellowship-trained orthopedic trauma surgeon) independently classified the fractures according to the AO-classification, based on initial radiographs. The cause of the fall was noted, e.g. "klunen" (walking on ice skates over land when there is insufficient ice, such as under a bridge) or falls due to cracks in the ice, and if the patients wore wrist protection. Number of visits to the outpatient clinics, cast rooms and of X-rays and CT scans were noted.

All patients gave written informed consent, and the local medical ethical committee approved the study (registration number 09.17.0390, March 18, 2009).

\section{Results}

\section{Patient characteristics}

A total of 97 patients have visited the EDs with a distal radius fracture sustained while skating on natural ice. Of these, seven were treated by the pediatric surgery department and were unavailable for follow-up. (X-rays showed six greenstick fractures treated conservatively and one antebrachial fracture treated by closed reduction at the operating theater). We thus included 90 patients with 92 fractures with an average age of 54 years (range 10-74 years). There were 24 men with an average age of 48.1 years (range 11-73 years) and 66 women ( 2 women with 2 fractures) with an average age of 56.2 years (range 10-74 years) (Table 1).

Incidence

In 2008, in a similar period of 9 days in the beginning of January, including two weekends, showed an incidence of 
Table 1

\begin{tabular}{lc}
\hline Fracture type & Number \\
\hline A2 & 27 \\
A3 & 23 \\
B1 & 4 \\
B2 & 6 \\
B3 & 1 \\
C1 & 7 \\
C2 & 18 \\
C3 & 6 \\
\hline
\end{tabular}

18 distal radius fractures in 18 patients in our three hospitals. The incidence of all distal radius fractures was 119 fractures in 117 patients, of which 99 fractures in 97 patients were ice skating related. Not surprisingly, the cause of the excluded fractures was still related to slippery conditions due to the cold weather. Natural ice skatingrelated fractures accounted thus for a 5.5-fold increase compared to the previous year.

Fall mechanism

The trauma mechanism for $90 \%$ of the patients was a fall backwards and for the others sideways or forwards. Sixty-five falls were at low skating speeds or while standing still. Three patients sustained their injury while they were transferring on land from one canal to another on a carpet or crossing a bridge because the ice underneath was not sufficiently strong to skate on, both of which is called "klunen" in Dutch. There were no reports of a direct collision with other skaters, but seven patients fell down trying to avoid collision with another skater. The falls at higher speeds, 15 patients, were caused by cracks in the ice, reeds, twigs or unevenness of the ice. None of the patients wore wrist protection.

Fracture characteristics

Fracture classification according to AO: 27 fractures type A2, 23 fractures type A3, 4 fractures type B1, 6 fractures type B2, 1 fracture type $\mathrm{B} 3,7$ fractures type $\mathrm{C} 1,18$ fractures type $\mathrm{C} 2$ and 6 fractures type $\mathrm{C} 3$ (Fig. 2).

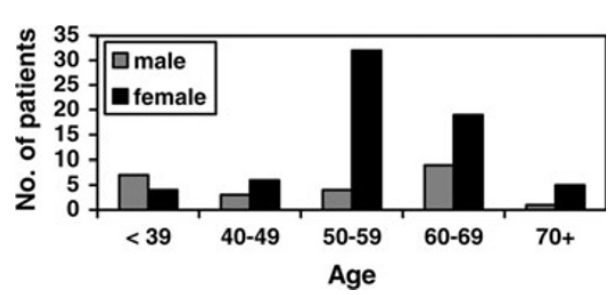

Fig. 2 Age distribution
Fracture management

During the initial visit at the emergency department, 28 patients (28 fractures) were treated with a cast without the need for reduction, in 54 patients (55 fractures) a single attempt at reduction was performed and in 9 patients (9 fractures) two attempts were undertaken. The nonoperative group consisted of 67 patients with 68 fractures (18 men and 49 women) with an average age of 55.5 (range 10-74 years) and were treated with a cast for an average of 5.5 weeks (range 3-12 weeks). Twenty-three patients were operated on 24 fractures, either acute $(n=3$, within one day) or delayed ( $n=21$, between 2 and 23 days). The operatively treated group consisted of 23 patients with 24 fractures (6 men and 17 women) with an average age of 56.6 (range 33-73 years).

The outpatient clinic was visited 269 times in 12 weeks with 218 X-rays, 9 CT scans (7 resulted in surgery and 2 resulted in conservative treatment) and 147 visits to the cast room for changing/removing casts.

\section{DASH score}

At 3 months, 80 patients responded by answering the Quick DASH questionnaire, 60 patients treated conservatively and 20 patients treated surgically.

Quick DASH score for the whole group, including conservative and surgical treatment: a mean of 23.1 points, SD 20.3 (95\% CI 18.6-27.6) and range 0-95. The conservative group: a mean of 19.9 points, SD 19.9 (95\% CI $14.7-25,0)$ and range $0-95$ and the surgically treated group: mean 31.7 points, SD 19.1 (95\% CI 23.4-40.4) and range $2-65$.

\section{Skating experience}

Sixty-eight percent of patients had not skated for more than 10 years, with at least some experience before that time. Twenty-six percent were trained skaters who on a regular basis practised on artificial skating rinks over the past year. Six percent of the patients had never skated before.

\section{Discussion}

Key findings

We found a high prevalence of patients, predominantly women, aged 50 and over, with a distal radius fracture, none of these patients wore wrist-protecting devices. Many of the patients described a desire for skating, after many years of non-skating due to lack of conditions. An often phrased word with respect to their skating technique was 
"rusty", and many falls were due to a minor loss of balance at low speeds, resulting in a fall backwards on the outstretched unprotected hands.

Strengths and limitations

Our study is strengthened due its multicenter setting. Furthermore, we prospectively evaluated patients using a validated outcome instrument with an intensive follow-up. Lack of a control group limits inferences on the possible effect of wrist-protecting devices. Finally, we did not evaluate all skating incidents in The Netherlands during the natural ice period. However, our findings warrant further research on protective measures during natural ice periods.

\section{Previous literature}

The fracture of the distal radius is the most common fracture in humans [2]. The first peak in the incidence is in adolescence, when it is due to sports in general [6] and risky outdoor pastimes such as in-line skating, skateboarding [5] and snowboarding [8]. The second peak is in post-menopausal women, who, due to hormonally induced osteoporosis, can fracture their wrist even in minor trauma. Several publications have shown an increase in hospital and emergency department attendance and increase in distal radius fractures after the installation of an ice skating rink with artificial surface ice in the area of that particular hospital [1, 3, 4, 11]. Attendance of a predominately mature female population is not mentioned in these articles, either at the ice skating rink or at the EDs.

In a randomized, controlled trial including 721 snowboarders, Machold et al. [7] found the use of wrist protection to lower the incidence of severe wrist injuries in snowboarders, especially for beginners in this sport . Schriber et al. [9] found that wrist injuries in in-line skating could be reduced by $87 \%$ by wearing wrist guards, and generally spoken, when renting out in-line skates, wrist protection is supplied by the rental agency. We hypothesized an increase of the incidence of distal radius fractures due to ice skating conditions. We found a 5.5-fold increase of fractures due to skating alone. All EDs in The Netherlands reported over-crowded waiting rooms and stretched resources, implying a similar increase in wrist fractures at all hospitals in The Netherlands.

The distal radius fractures, which were treated conservatively, were predominantly extra-articular type A fractures (according to AO-classification) and fractures with little comminution or dislocation resulting from lowenergy trauma. The difference in the Quick DASH scores between the conservatively and surgically treated groups can be explained by the difference in fracture types and severely displaced and intra-articular pattern, leading to higher Quick DASH outcomes at 3 months.

Implications of our study

Our experience, both at different ice skating locations and at the EDs, confirmed that in The Netherlands, no wrist protection is used when ice skating. Our findings suggest that, especially for a mature audience, protective wrist devices, as universally used in in-line skating, could reduce the incidence of wrist fractures during ice skating, assuming that the fall mechanism of in-line skating is similar to natural ice skating.

\section{Conclusion}

We hope that our findings will raise the awareness of the medical profession and the general population to the hazards of skating on natural ice in The Netherlands, and these data might suggest that protective devices could prevent some of the fractures sustained during a period of natural ice, especially in women over 50 years of age.

Acknowledgment We did not have technical help, financial or other sponsorship. There are no conflict of interest.

Open Access This article is distributed under the terms of the Creative Commons Attribution Noncommercial License which permits any noncommercial use, distribution, and reproduction in any medium, provided the original author(s) and source are credited.

\section{References}

1. Clarke HJ, Ryan D, Cullen I, Cusack S (2006) The impact of a temporary ice-rink on an emergency department service. Eur J Emerg Med 13(4):204-208

2. Court-Brown CM, Caesar B (2006) Epidemiology of adult fractures: a review. Injury 37(8):691-697

3. Dillon JP, Geurin S, Laing AJ, Ryan D, Dolan M (2006) The impact of ice-skating injuries on orthopaedic admissions in a regional hospital. Ir Med J 99(1):7-8

4. Kelsall NK, Bowyer GW 2009 Injuries sustained at a temporary ice-skating rink: prospective study of the Winchester experience 2007-2008. Injury (Epub ahead of print)

5. Kyle SB, Nance ML, Rutherford GW Jr, Winston FK (2002) Skateboard-associated injuries: participation-based estimates and injury characteristics. J Trauma 53(4):686-690

6. Lawson GM, Hajducka C, McQueen MM (1995) Sports fractures of the distal radius-epidemiology and outcome. Injury 26(1):33-36

7. Machold W, Kwasny O, Eisenhardt P, Kolonja A, Bauer E, Lehr S, Mayr W, Fuchs M (2002) Reduction of severe wrist injuries in snowboarding by an optimized wrist protection device: a prospective randomized trial. J Trauma 52(3):517-520

8. Russell K, Hagel B, Francescutti LH (2007) The effect of wrist guards on wrist and arm injuries among snowboarders: a systematic review. Clin J Sport Med 17(2):145-150 (Review) 
9. Schriber RA, Branch-Dorsey CM (1995) In-line skating injuries. Epidemiology and recommendations for prevention. Sports Med 19(6):427-432

10. Veehoff MM, Sleegers EJ, van Veldhoven NH, Schuurman AH, van Meeteren NL (2002) Psychometric qualities of the Dutch language version of the Disabilities of the Arm, Shoulder and Hand questionnaire (DASH-DLV). J Hand Ther 15(4):347-354 11. Williamson DM, Lowdon IM (1986) Ice-skating injuries. Injury 17(3):205-207 